\title{
ASSESSING THE THERAPEUTIC ROLE OF JOSHANDA: PHYTOCHEMICAL, ANTIOXIDANT, ANTI- INFLAMMATORY AND ANTIMICROBIAL ACTIVITIES
}

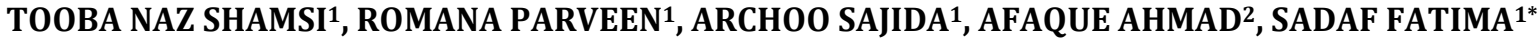

${ }^{1}$ Department of Biotechnology, Jamia Millia Islamia, New Delhi 110025, India, ${ }^{2}$ School of Biotechnology, Jaipur National University, Jaipur, Rajasthan

Email: amu.jmi@rediffmail.com

Received: 07 Sep 2017 Revised and Accepted: 22 Nov 2017

\begin{abstract}
Objective: Joshanda, a polyherbal Unani formulation is extensively used as a common home remedy for the treatment of a cough and cold accompanied by pharyngeal inflammation and fever. This study aimed to analyze phytochemicals, antioxidant, anti-inflammatory, and antibacterial activity.

Methods: The study investigated the presence of phyto-compounds in joshanda and antioxidant, antibacterial, anti-fungal, and anti-inflammatory activities by various in vitro standard methods using ascorbic acid, ampicillin, and aspirin respectively as standard drugs.

Results: Joshanda aqueous extract revealed the presence of tannins, phenols, flavonoids glycosides, terpenoids, and alkaloids and absence of sterols, saponins, xanthoprotiens, and carboxylic acid. Joshanda showed the highest inhibition against B. subtilis (\% MGI 99.000 \pm 0.577 ) and least inhibition against P. aeruginosa (\%MGI of 84.102 \pm 0.491 ). Joshanda extract, ascorbic acid demonstrated highest $\%$ DPPH radical scavenging of $98.379 \pm 0.313 \%$, $98.843 \pm 0.443 \%$ and a minimum of $36.210 \pm 1.174 \%, 83.192 \pm 0.422 \%$. Results showed $\mathrm{H}_{2} \mathrm{O}_{2}$ scavenging activity of $0.047 \pm 0.001 \mu \mathrm{g} / \mathrm{ml} \mathrm{per} \mathrm{minute}$ degradation of $\mathrm{H}_{2} \mathrm{O}_{2}$. FRAP value was observed in joshanda and ascorbic acid with a maximum of $0.945 \pm 0.024,0.687 \pm 0.047 \mathrm{mmol}$ and minimum of $0.171 \pm 0.036,0.059 \pm 0.005 \mathrm{mmol}$ respectively. Joshanda extract showed the highest albumin denaturation inhibition of $14.069 \pm 0.350 \%$ and the lowest of $1.880 \pm 0.194 \%$ at extract volume of $1000 \mu \mathrm{l}$ and $100 \mu \mathrm{l}$ respectively. The extract demonstrated the highest proteinase inhibition of $24.003 \pm 0.291 \%$ and the lowest of $4.959 \pm 0.254 \%$ comparable to aspirin. Joshanda had no potent anticandidal activity up to $1 \mathrm{mg} / \mathrm{ml}$.
\end{abstract}

Conclusion: Results clearly suggested that joshanda is a potent phytodrug and can also be used as a strong reactive oxygen species scavenger, might be used as anti-arthritic and strong natural antibiotic agent for effective treatment of various oxidative stressed disorders.

Keywords: Joshanda, Antioxidant, Antibacterial, Anti-inflammatory, Unani, Biological relevance

(C) 2018 The Authors. Published by Innovare Academic Sciences Pvt Ltd. This is an open access article under the CC BY license (http://creativecommons.org/licenses/by/4.0/) DOI: http://dx.doi.org/10.22159/ijpps.2018v10i2.22450

\section{INTRODUCTION}

In the recent years, there has been a great switchover in the universal trend of medicine selection from synthetic to herbal medicine, which indicates "Return to Nature". Medicinal plants have been best known for millennial and are highly important all over the world as a rich source of therapeutic agents for the prevention and cure of diseases and ailments [1]. The global rise in demand for herbal medicines has led to the decline in their quality as there is a lack of adequate regulations pertaining to drugs [2]. World health organization (WHO) has highly emphasized the need to ensure quality control of medicinal plant products by the use of modern techniques and by applying suitable parameters and standards. In order to overcome inevitable shortcomings of the pharmacopeia monograph other different quality control measures must be explored. [3-6]. Out of 255 drugs (which are considered as basic and essential by the WHO, $11 \%$ is extracted from plants, and many synthetic drugs are also extracted from natural precursors.

Phytochemicals are known to possess antioxidant, antibacterial, antifungal, antidiuretic, anti-inflammatory, and radioprotective activity [7-13], and due to these properties, they are largely used and given preference for medicinal purpose. The development of drug resistance and the undesirable side effects of certain antibiotics have led to the search for new antimicrobial agents, mainly among plant kingdom, to find leads with unique chemical structures which may exert a hitherto unexploited mode of action. Obtaining potential and basic benefits from plants, always been a field of speculation for researchers and has formed the basis for the development of drugs to treat various diseases. Henceforth, screening of plants for the presence of natural products and beneficial properties presents a major avenue. The resistance acquired by microbes to the existing antibiotics demands increased efforts in the development of new antibiotics. Although various plants with antimicrobial potential have been identified, a great number still remains unidentified. High range of climatic variation from tropical to alpine leads to the richness in biological diversity. Many kinds of plants are pervasive in India and many of them have been used for antimicrobial assay [14]. There is a dire need of extensive hard studies of medicinal plants found with a special reference to their properties to fight against microbial diseases. Therefore, qualitative phytochemical screening of these phyotdrugs is a step towards 'cure by nature'. "Joshanda", a Persian word with a meaning "prepare by boiling". Unani medicines are usually taken as aqueous extracts containing some water-soluble organic principles and mostly inorganic ion compounds. The most frequently used formulation of joshanda consists of seven ingredients [35]. Joshanda has been especially used in the treatment of cold, cough, and related allergic disorders. It has been reported to possess antihistamine, antitussive, expectorant, antipyretic, and anti-inflammatory activities [36, 37]. The main composition of joshanda has been given in table 1 . In the market, joshanda is available in the form of a dry mixture.

This article aims to assess the presence of phytochemicals in the aqueous extract of joshanda. Further, we have assessed the in vitro antioxidant, anti-inflammatory, antibacterial, and antifungal activities of the aqueous extract of joshanda. This is the first report (to the best of our knowledge) till date on this kind of study where the aqueous extract of joshanda was evaluated for various phytocompounds and biological activities. 
Table 1: The main composition of joshanda

\begin{tabular}{llll}
\hline S. No. & Scientific name & Common name & Part used \\
\hline 1. & Althea officinalis & Khatmi & seeds \\
2. & Cordia latifolia & Sapistan & dried fruit \\
3. & Glycyrrhiza glabra & Mulethi & dried rhizomes \\
4. & Malvaro tundifolia & Khubbazi & seeds \\
5. & Onosma bracteatum & Gaozaban & leaves \\
6. & Viola odorata & Banafsha & flowers \\
7. & Zizyphus jujuba & Unnab & dried fruit \\
\hline
\end{tabular}

\section{MATERIALS AND METHODS}

\section{Sample preparation}

$10 \mathrm{gm}$ of joshanda with all seven components in equimolar ratio were boiled in $200 \mathrm{ml}$ of distilled water at $100{ }^{\circ} \mathrm{C}$ for $30 \mathrm{~min}$ to make a decoction of final volume $100 \mathrm{ml}$. The extract was then filtered using a muslin cloth. The filtrate was then centrifuged and the supernatant was obtained. This served as an aqueous extract of joshanda for the further phytochemical screening and in vitro biological studies.

\section{Chemicals and reagents}

All the chemicals (analytical grade) used for phytochemical screening, antioxidant, anti-inflammatory and antibacterial assay were purchased from Merck, SRL, and Himedia. DPPH (1, 1diphenyl-2-picrylhydrazyl) and TPTZ (2, 4, 6-tris (2-pyridyl)-Striazine) were purchased from Sigma-Aldrich.

\section{Phytochemical screening}

Various standardized qualitative chemical tests were performed for qualitative determination of different phytoconstituents present in the aqueous extract of joshanda by the method of Harborne with some modifications [38].

\section{Evaluation of antibacterial potential of joshanda \\ Test microorganisms}

The basic four clinical isolates of bacteria used for the study are Staphylococcus aureus (MTCC 902), Escherichia coli (MTCC 443), and Bacillus subtilis (MTCC 736), Pseudomonas aeruginosa (MTCC 2453). Their cultures were procured from NCCS, Pune, India and maintained on nutrient agar plates at $4{ }^{\circ} \mathrm{C}$.

\section{Broth dilution method}

Antimicrobial activity of the aqueous extract of joshanda was tested against four bacterial strains, out of which two of them were grampositive bacteria (B. subtilis and $S$. aureus) and the other two were gram-negative bacteria ( $E$. coli and $P$. aeruginosa) by the method of Barbade and Datar with some modifications [15]. Cultures were prepared overnight in Luria broth (LB) media by inoculation with a single colony from agar plates and incubated for $12 \mathrm{~h}$ at $37^{\circ} \mathrm{C}$. These cultures were diluted with fresh LB media to approximately $10^{4}$ colony forming units (CFU) and incubated at $37^{\circ} \mathrm{C}$ for $12-14 \mathrm{~h}$ in the presence of joshanda extract analogized to the growth of the control culture where media and bacterial inoculums were only taken. The experiment was performed in triplicates $(n=3)$. The percentage inhibition was calculated by using the following formula.

$$
\text { Mean Growth Inhibition (\%) =[(dc-dt)/dc] x } 100
$$

Where dc and dt represent the absorbance of control and treated sample strains at $600 \mathrm{~nm}$ respectively.

\section{Agar well diffusion method}

To determine the antibacterial activity of joshanda, agar well diffusion method was used. The log phase bacterial cultures (secondary culture) was spread on LB agar medium plates by using a sterile spreader in order to get a uniform bacterial growth on test plates. A sterile cork borer was used to punch the wells over the agar plates. About 10-20 $\mu \mathrm{l}$ of each extract was added using sterile syringe into wells and kept at room temperature for $2 \mathrm{~h}$ for diffusion.
Ampicillin $(10 \mathrm{mg} / \mathrm{ml})$ was used as the standard antibacterial drug. The plates were then incubated at $37^{\circ} \mathrm{C}$ for $18-24 \mathrm{~h}$. The diameter of the inhibition zone $(\mathrm{mm})$ was calculated. The results (zone of inhibition) were compared with the activity of the standard. The experiment was repeated 2 times for the confirmation

\section{Determination of anti-inflammatory activity}

\section{Inhibition of albumin denaturation}

The anti-inflammatory activity by inhibition of albumin denaturation was done using the method of Mizushima et al. [16] with minor changes. A wide range of diluted working solutions of the joshanda and its constituents plants were prepared and mixed with $1 \%$ aqueous solution of bovine serum albumin (BSA) fraction. The samples were incubated at $37^{\circ} \mathrm{C}$ for $20 \mathrm{~min}$ and then heated at $57^{\circ} \mathrm{C}$ for $20 \mathrm{~min} .1 \%$ BSA was taken as control and Tris buffer was taken as blank. Aspirin $(100 \mu \mathrm{g} / \mathrm{ml})$ was taken as a standard drug. After few minutes of cooling the samples, the turbidity was studied at $660 \mathrm{~nm}$. The experiment was performed in triplicates $(n=3)$. Percent inhibition of protein denaturation was calculated by the formula.

$\%$ inhibition $=($ Abs control-Abs sample $) \times 100 /$ Abs control

\section{Proteinase inhibitory action}

The experiment was executed according to the revised procedure of Oyedepo et al. [17]. The reaction mixture ( $2 \mathrm{ml}$ ) contained $1 \mathrm{ml} 20$ mmol Tris $\mathrm{HCl}$ buffer ( $\mathrm{pH}$ 7.4), $1 \mathrm{ml}$ test sample of different concentrations, and $0.06 \mathrm{mg}$ trypsin. The mixture was incubated at $37{ }^{\circ} \mathrm{C}$ for $5 \mathrm{~min}$ followed by addition of $1 \mathrm{ml}$ of $0.8 \%(\mathrm{w} / \mathrm{v})$ casein. The mixture was again incubated for further $20 \mathrm{~min}$. At the end, $2 \mathrm{ml}$ of $70 \%$ perchloric acid was added to finish the reaction. The absorbance of the supernatant was read at $210 \mathrm{~nm}$ against buffer as blank, after removing the cloudy suspensions through the centrifuge. The experiment was performed in triplicates $(n=3)$. Further, the percentage inhibition of proteinase inhibitory activity was determined by the following formula.

$\%$ proteinase inhibition $=($ Abscontrol-Absbsample $) \times 100 /$ Abscontrol Determination of antioxidant activity

\section{Catalase (CAT) assay}

Catalase activity was assayed following the method of Jambunathan et al. with minor modification [18]. $\mathrm{H}_{2} \mathrm{O}_{2}$-Phosphate buffer (hydrogen peroxide-phosphate buffer) $(3.0 \mathrm{ml})$ was taken in an experimental cuvette, followed by the rapid addition of $40 \mu \mathrm{l}$ of joshanda and mixed thoroughly. The time required for a drop in absorbance by 0.05 units was noted at $240 \mathrm{~nm}$. The $\mathrm{H}_{2} \mathrm{O}_{2}$-Phosphate buffer was served as control. CAT activity in each sample was expressed in $\mathrm{nmol} / \mathrm{min} / \mathrm{ml}$. One unit was defined as the amount of enzyme that caused the formation of $1.0 \mathrm{nmol}$ of formaldehyde per minute at $25^{\circ} \mathrm{C}$. The experiment was performed in triplicates $(n=3)$.

\section{1, 1 Diphenyl-1-(2, 4, 6-trinitrophenyl) hydrazyl (DPPH) assay}

The antioxidant activity of joshanda was checked on the basis of the free radical scavenging effect of the stable DPPH according to the protocol of Goveas and Abraham with minor modifications [19]. A wide range of diluted working solutions of joshanda was prepared in distilled water and methanol respectively. $0.1 \mathrm{mmol}$ DPPH was prepared in $80 \%$ methanol and $500 \mu \mathrm{l}$ of this solution was mixed with $500 \mu \mathrm{l}$ of working sample solutions and standard solution separately. Ascorbic acid $(1 \mathrm{mg} / \mathrm{ml})$ in distilled water was used as 
the standard. These solution mixtures were kept in dark for $30 \mathrm{~min}$ and optical density was measured at $517 \mathrm{~nm}$. $0.1 \mathrm{mmol}$ DPPH solution was used as the control. The range of diluted aqueous extracts was taken as blank. The experiment was performed in triplicates $(n=3)$. The optical density was recorded and DPPH scavenging was calculated using the given formula.

$$
\text { DPPH scavenging Activity (\%)=[(dc-dt)/dc] x } 100
$$

Where dc and dt represent absorbance of control and test sample respectively at $517 \mathrm{~nm}$.

\section{Ferric reducing antioxidant power (FRAP) assay}

Antioxidant activity assay was assessed based on the FRAP assay by the method of Sudha et al. with minor modification [20]. FRAP reagents were freshly prepared by mixing $10 \mathrm{ml}$ acetate buffer $(300$ mmol, pH 3.6), $1 \mathrm{ml} \mathrm{TPTZ} \mathrm{solution} \mathrm{(10} \mathrm{mmol} \mathrm{TPTZ} \mathrm{in} 40 \mathrm{mmol} / \mathrm{l} \mathrm{HCl}$ ) and $1 \mathrm{ml} \mathrm{FeCl}_{3}(20 \mathrm{mmol})$ water solution. A range of diluted working solutions of the joshanda was prepared in distilled water. Each sample $(200 \mu \mathrm{l})$ was added in $1.5 \mathrm{ml}$ of freshly prepared FRAP reagent and mixed and after $5 \mathrm{~min}$, absorbance was measured at $593 \mathrm{~nm}$, using the working solution of FRAP as blank. The standard antioxidant used was ascorbic acid. The results were expressed in $\mathrm{mmol} \mathrm{Fe} e^{2+} / \mathrm{ml}$ of aqueous extract. The experiment was performed in triplicates $(n=3)$. Higher absorbance indicated higher reducing power.

\section{Estimation of reduced glutathione (GSH)}

Reduced glutathione was estimated by following the method described by Moron et al. [21]. Reduced glutathione, when reacted with DTNB (5, 5'-dithiobis nitrobenzoic acid), gave a yellow colored product that absorbed at $412 \mathrm{~nm}$. A homogenate was prepared with $0.5 \mathrm{~g}$ of the plant sample along with $2.5 \mathrm{ml}$ of $5 \%$ trichloroacetic acid (TCA). The precipitated protein was centrifuged at $1000 \mathrm{rpm}$ for 10 min. The supernatant $(0.1 \mathrm{ml})$ of the mixture was further used for the determination of GSH. The supernatant $(0.1 \mathrm{ml})$ was composed of $1.0 \mathrm{ml}$ with $0.2 \mathrm{M}$ sodium phosphate buffer ( $\mathrm{pH} 8.0)$. Standard GSH corresponding to concentrations ranging between 2 and 10 moles was also prepared. Two ml of freshly prepared DTNB solution was added and the intensity of the yellow color developed was measured in a spectrophotometer at $412 \mathrm{~nm}$ after $10 \mathrm{~min}$. The values were expressed as $\mathrm{n}$ moles GSH/g sample. The experiment was performed in triplicates $(n=3)$.

\section{Determination of antifungal activity}

The determination of the minimum inhibitory concentration of joshanda extract against Candida cells (ATCC 10261 and ATCC 90028) by broth dilution was carried by the method given by the Clinical and laboratory standards institute (CLSI). Different cultures were grown with or without test compounds in the media. Two-fold dilutions of the test compound were carried out as an initial step. Candida cells $\left(10^{5} \mathrm{cells} / \mathrm{ml}\right)$ were inoculated in molten yeast extract peptone dextrose (YEPD) agar $\left(\sim 40^{\circ} \mathrm{C}\right)$ and poured into Petri plates. Also, the antifungal activity of aqueous extract in solid media was determined by the disc diffusion method. Different concentrations of test compounds were spread on the disc placed on solid agar in $10 \mu \mathrm{l}$ volume. The average diameter of the zone of inhibition was measured in millimetres. The experiment was performed in triplicates $(n=3)$.

\section{RESULTS}

\section{Phytochemical screening}

The phytochemical analysis of the aqueous extract of joshanda revealed the presence of phytochemicals. An adequate amount of tannins, phenols, flavonoids glycosides, terpenoids, and alkaloids were found in the aqueous extract. However, screening depicted the absence of sterols, saponins, xanthoprotiens, and carboxylic acid. The results obtained are depicted in table 2 .

Table 2: Phytochemical composition of aqueous extract of joshanda

\begin{tabular}{|c|c|c|}
\hline S. No. & Phytochemical constituent & Result \\
\hline 1. & Terpenoids & Positive \\
\hline 2. & Phenols & Positive \\
\hline 3. & Carboxylic acid & Negative \\
\hline 4. & Flavonoids & Positive \\
\hline 5. & Glycosides & Positive \\
\hline 6. & Xanthoproteins & Negative \\
\hline 7. & Tannins & Positive \\
\hline 8 & Sterol & Negative \\
\hline 9. & Saponins & Negative \\
\hline 10. & Alkaloids & Positive \\
\hline
\end{tabular}

\section{Determination of antibacterial activity of joshanda}

\section{Broth dilution assay}

Antibacterial assay of joshanda was examined against various bacterial strains by accessing the percentage inhibition in presence of the extract. A range of various concentrations of extract was tested against four different strains of bacteria. It was found that joshanda had strongest inhibitory activity against $B$. subtilis with \%MGI of $99.000 \pm 0.577$ whereas; it showed the least inhibition against $P$. aeruginosa with \% MGI of $84.102 \pm 0.491$. The results were quite comparable to ampicillin which showed almost complete inhibition against all the bacterial strain. The extent of inhibition increased with length of incubation and increase in concentration. Hence, the results showed that joshanda exhibit bactericidal property in vitro i.e. the growth of microorganisms was inhibited in its presence in time and concentration-dependent manner (fig. 1).

\section{Well diffusion assay}

The aqueous extract of joshanda was also tested for antibacterial activity in agar medium using well diffusion assay by determining the zones of inhibition. The results showed fair growth in control conditions where no drug/extract was taken. Based on the zone of inhibition produced, joshanda proved to exhibit the good antibacterial activity which was quite comparable to the standard drug (ampicillin) reflected through inhibition zone of almost similar diameter (table 3).

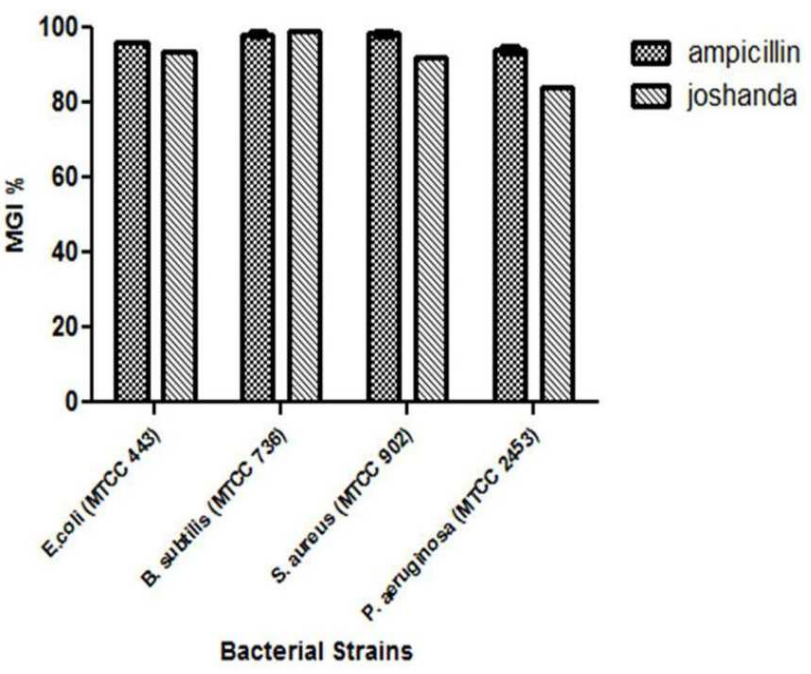

Fig. 1: Antibacterial activity of joshanda aqueous extract against B. subtilis, $S$. aureus, $E$. coli and $P$. aeruginosa by calculating \% Mean Growth Inhibition, results represent the means \pm SEM from at least three separate experiments 
Table 3: Zone of inhibition (mm) produced by control, ampicillin and joshanda aqueous extract when tested against $E$. coli and $S$. aureus expressed as mean \pm SEMrespectively

\begin{tabular}{lll}
\hline Components & Zone of inhibition (mm) & \\
\cline { 2 - 3 } & E. coli & S. aureus \\
\hline Control & No zone of inhibition & No zone of inhibition \\
Ampicillin & $25 \pm 0.851$ & $24 \pm 0.921$ \\
Joshanda aqueous extract & $17 \pm 0.798$ & $15 \pm 0.826$ \\
\hline
\end{tabular}

Determination of antioxidant activity

\section{DPPH assay}

DPPH radical scavenging assay is the most extensively used method for screening antioxidant activity since it can furnish many samples in a short period and detect active ingredients at low concentration. The decrease in the absorbance of the DPPH radical caused by antioxidant was due to the scavenging of the radical by hydrogen donation. It is visually notable as the color changes from purple to yellow. Joshanda aqueous extract showed DPPH radical scavenging activity in a concentration-dependent manner as shown in fig. 2 . The highest and lowest scavenging was observed at amount $500 \mu \mathrm{l}$ and $50 \mu \mathrm{l}$ of the extracts. Joshanda extract demonstrated highest \% DPPH radical scavenging of $98.379 \pm 0.313 \%$ and the minimum of $36.210 \pm 1.174 \%$.

The results were quite comparable to that of standard i.e. ascorbic acid with maximum \% DPPH scavenging of $98.843 \pm 0.443 \%$ and the minimum of $83.192 \pm 0.422 \%$. The scavenging activity of joshanda with $\mathrm{IC}_{50}$ (inhibitory concentration) value of $114.49 \mu \mathrm{g} / \mathrm{ml}$ was quite comparable to the scavenging activity of ascorbic acid with $\mathrm{IC}_{50}$ value $60.55 \mu \mathrm{g} / \mathrm{ml}$ taken as standard.

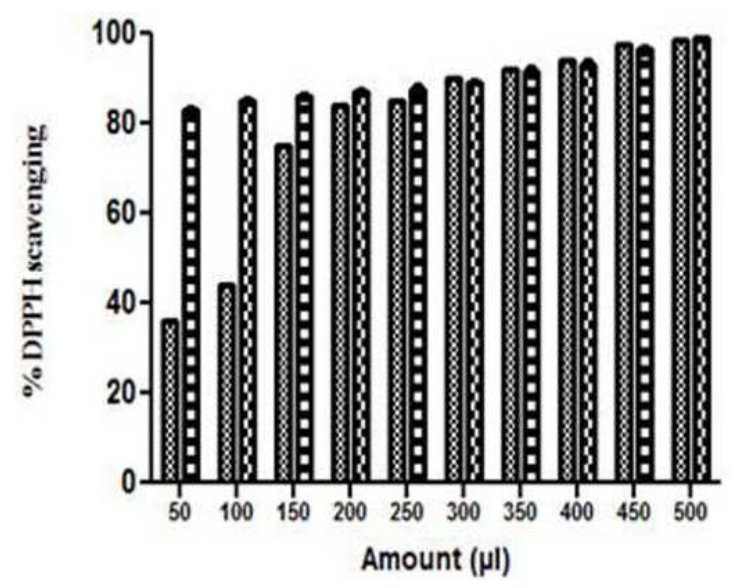

짔 Joshanda

$\mathbf{B}$ Ascorbic acid

Fig. 2: DPPH free radical scavenging activity of joshanda were calculated and compared to ascorbic acid i.e. standard. The activity increased in time and concentration-dependent manner, results represent the mean \pm SEM from at least three separate experiments

\section{CAT assay}

Hydrogen peroxide $\left(\mathrm{H}_{2} \mathrm{O}_{2}\right)$ is a non-radical reactive oxygen species with weak oxidizing activity. It diffuses through cell membranes rapidly and interacts with $\mathrm{Fe}^{2+}$ and possibly $\mathrm{Cu}^{2+}$ ions to form hydroxyl radicals and other free radicals. It is therefore biologically advantageous for cells to control the amount of $\mathrm{H}_{2} \mathrm{O}_{2}$ that is allowed to accumulate. The $\mathrm{H}_{2} \mathrm{O}_{2}$ scavenging ability of the aqueous extract of joshanda is shown in fig. 3.

The results show that joshanda exhibited significant $\mathrm{H}_{2} \mathrm{O}_{2}$ scavenging activity i.e. $0.047 \pm 0.001 \mu \mathrm{g} / \mathrm{ml}$ per minute degradation of $\mathrm{H}_{2} \mathrm{O}_{2}$ (fig. 3).

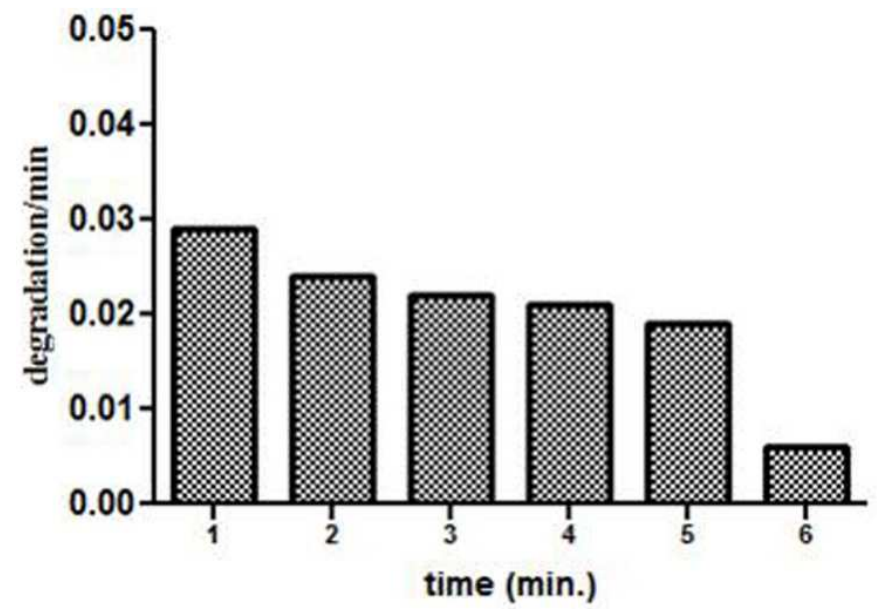

Fig. 3: $\mathrm{H}_{2} \mathrm{O}_{2}$ scavenging (\%) was assessed with increasing amount of joshanda extract. The $\mathrm{H}_{2} \mathrm{O}_{2}$ degradation increased in concentrationdependent manner, results represent the means \pm SEM from at least three separate experiments 


\section{FRAP assay}

The ferric reducing antioxidant power of joshanda is shown in fig. 4 . The results showed that FRAP value of joshanda increase in the concentration-dependent manner. The highest absorbance of FRAP was observed in joshanda at $500 \mu \mathrm{l}$ and the lowest was at $50 \mu \mathrm{l}$ with maximum FRAP value $0.945 \pm 0.024 \mathrm{mmol}$ and the minimum value of
$0.171 \pm 0.036 \mathrm{mmol}$ respectively as compared to the standard which showed maximum FRAP value of $0.687 \pm 0.047 \mathrm{mmol}$ and minimum at $0.059 \pm 0.005 \mathrm{mmol}$ respectively. These concentrations were effective to react with ferric tripyridyltriazine (Fe III-TPTZ) complex and produce a blue colored ferrous tripyridyltriazine (Fe II-TPTZ). From the observations, it is clear that joshanda showed fair antioxidant activity comparable to ascorbic acid.

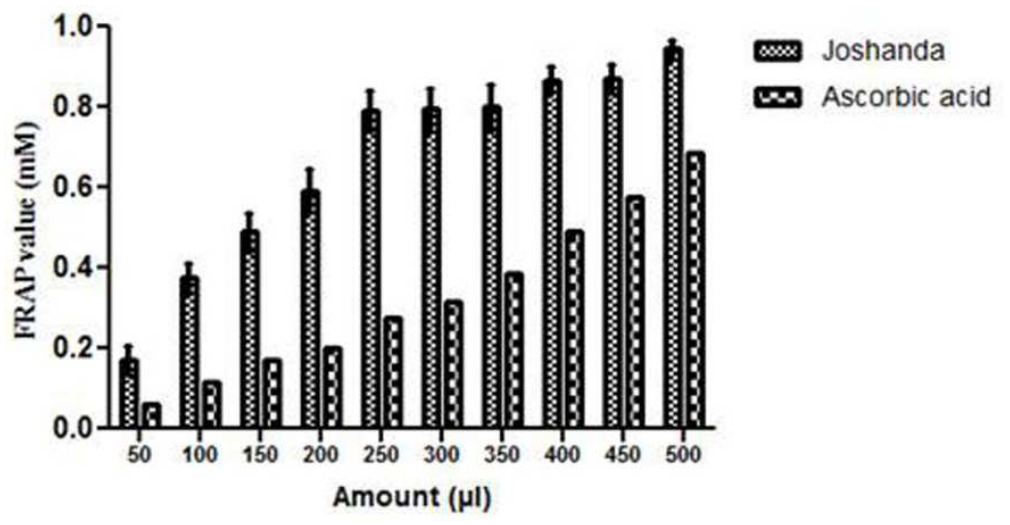

Fig. 4: FRAP value of joshanda extract was estimated and compared to the ascorbic acid as standard. The results were expressed in mmol, results represent the means \pm SEM from at least three separate experiments

\section{Evaluation of anti-inflammatory activity of joshanda}

\section{Inhibition of albumin denaturation}

Joshanda has mild anti-inflammatory property. If there occurs any infection or damage to the body or tissue then body show response against the infection through inflammation. Protein denaturation has to be one of the major causes of inflammation. Due to this, we have tried to find out the ability of joshanda to inhibit protein denaturation. The results showed that joshanda was effective in inhibiting thermally induced albumin denaturation at different concentrations (fig. 5). The joshanda extract showed the highest percentage inhibition of albumin denaturation of $14.069 \pm 0.350 \%$ and the lowest of $1.880 \pm 0.194 \%$ at extract volume or amount of $1000 \mu \mathrm{l}$ and $100 \mu \mathrm{l}$ respectively. The $\mathrm{IC}_{50}$ value of joshanda was found out to be $2.005 \mathrm{mg} / \mathrm{ml}$. Aspirin which was used as standard drug showed the inhibition of $71 \pm 0.396 \%$ at $100 \mu \mathrm{g} / \mathrm{ml}$.

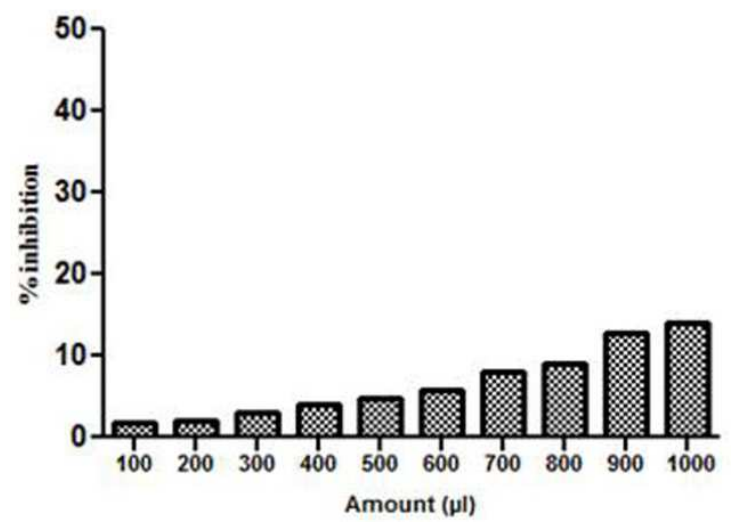

Fig. 5: Inhibition of albumin denaturation activity of joshanda was checked at various concentrations taking aspirin (100 $\mu \mathrm{g} / \mathrm{ml}$ ) as standard, results represent the means \pm SEM from at least three separate experiments

\section{Proteinase inhibitory assay}

The proteinase inhibitory assay showed that honey exhibits antiinflammatory property in a concentration-dependent manner.
Results exhibited significant anti-protease activity at different concentrations of joshanda extract. The extract demonstrated the highest percentage proteinase inhibition of $24.003 \pm 0.291 \%$ and the lowest of $4.959 \pm 0.254 \%$ at extract volume or amount of $1000 \mu \mathrm{l}$ and $100 \mu \mathrm{l}$ respectively (fig. 6). Aspirin which was used as standard showed the maximum inhibition of $87 \pm 0.311 \%$ at $1000 \mu \mathrm{g} / \mathrm{ml}$.

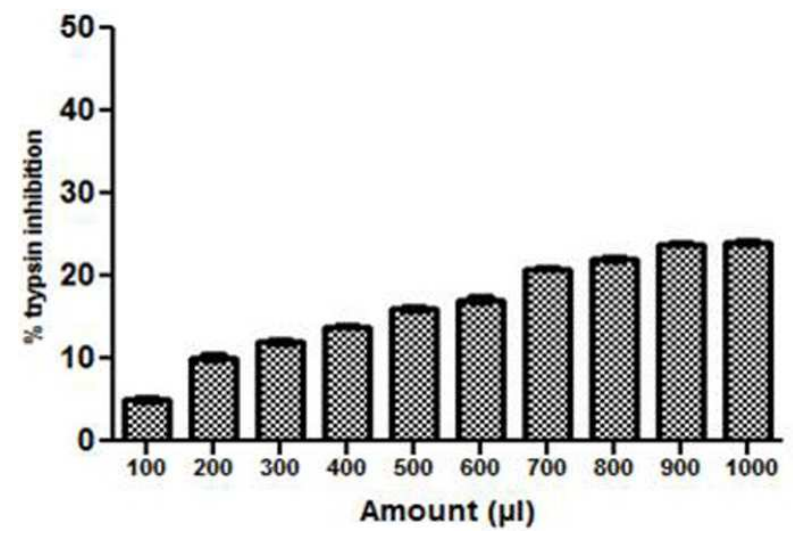

Fig. 6: \% inhibition of trypsin activity in presence of joshanda extract was evaluated, results represent the means \pm SEM from at least three separate experiments

\section{Determination of antifungal activity}

Antifungal assay of the joshanda and its constituents extract was performed against Candida cells (ATCC 10261 and ATCC 90028). The extract showed no zone of inhibition up to $2 \mathrm{mg} / \mathrm{ml}$ as well as there was no inhibition in growth of Candida cells. Our results showed that joshanda had no potent anticandidal activity up to $1 \mathrm{mg} / \mathrm{ml}$; increased concentration of extracts might lead the anticandidal effect.

\section{DISCUSSION}

The practice of traditional medicine (hikmath and homeopathy) is regulated by the Federal Government through Unani, Ayurvedic, and Homeopathic (UAH) Practitioners Act, 1965. In this regard, the National Council of Tibb (NCT) and National Council for Homeopathy $(\mathrm{NCH})$ were established as corporate bodies under 
section 3 of the Act. Their formation was aimed to encourage and popularize the traditional system of medicine in masses [22, 23]. Therefore, in this study, in vitro pharmacotherapeutic properties and phytoconstituents of joshanda were assessed.

Secondary metabolite such as alkaloids, tannins, flavonoids are known to have activity against pathogens and therefore aid the antimicrobial activities of medicinal plants [24] which contribute significantly towards the biological activities of medicinal plants such as hypoglycemic, anti-diabetic, antioxidant, antimicrobial, antiinflammatory, anti-carcinogenic, anti-malarial, anti-cholinesterase, anti-leprosy activities etc [25-32]. From the present study, it is found that the decoction of joshanda contains flavonoids, alkaloid, tannin, phenol, glycosides, and terpenoids which are of great importance in the field of drug research. Therefore, further study must aim to isolate and purify them to confirm their pharmacological and medicinal use [33].

Protein denaturation and membrane leakage are the main cause of inflammatory processes implicated in the pathogenesis of diseases and infections. Joshanda was tested for their potential property of anti-inflammatory using two assays, Albumin denaturation, where the inhibition coagulation of protein by joshanda was tested and also protease inhibition where the inhibition of trypsin was tested. In both the cases, joshanda showed the minimal efficacy in both the reactions thus confirming lack the anti-inflammatory properties at low concentrations [34].

Antioxidants are very important since they possess the ability to protect the body from damage caused by free radical induced oxidative stress [35]. The antioxidant potential of joshanda was investigated in the search for affirmation of efficacy of this unani drug as decoction obtained from natural resources. It became clear that joshanda presents high antioxidant activity compared with reference antioxidant Vitamin C for DPPH scavenging activity and FRAP. Also, it showed fair activity when assessed by other methods. Hence, joshanda is a promising candidate for use as natural antioxidant for the health of human being.

Alkaloids and flavonoids are known to possess antibacterial activity. The antibacterial mechanisms of action of selected flavonoids are attributed to inhibition of DNA gyrase, cytoplasmic membrane function, and licochalcones A and C energy metabolism [36]. These phytochemical acts as natural antibiotics by preventing lipid peroxidation or by iron deprivation, hydrogen bonding, or specific interactions with vital proteins such as enzymes in microbial cells. Joshanda, being rich in alkaloids and flavonoids demonstrated antibacterial activity against four bacterial strains, two grampositive and two gram-negative namely B. subtilis and $S$. aureus (gram positive) and $E$. coli and $P$. aeruginosa (gram-negative bacteria). The most significant finding in this study was that the heating treatment up to $100{ }^{\circ} \mathrm{C}$ could not impair the antibacterial action of the components. Till date, no antibiotic can withstand that heat treatment, to retain its antibacterial property. It would be of great significance if these heat stable and biologically active components are purified and characterized. The studies on purified antibacterial components and their cumulative action might indicate and elucidate their efficacy as future antibacterial remediation.

\section{CONCLUSION}

Joshanda was quantified for the main phytochemicals present in the extract. The presence of various phenolics and non-phenolics phytocompounds concluded that the plant might be of medicinal importance. The varying antioxidant (free radical scavenging) activities of extracts when compared to standard antioxidant i.e. Vitamin C, suggested the possibility that the antioxidant activity of this medicinal plant may contribute to play their role against various reactive oxygen species (ROS) mediated disorders such as cellular aging and cancer, becoming an alternative in the fight against skin aging and cancer cells. Altogether, these results establish the therapeutic applications of joshanda and its use as the herbal medicine for the prevention of inflammation and treatment of ROS and bacterial diseases. It can also be accomplished as an important mark in the field of human health and sciences. Finally, considering the results obtained, as future perspectives, we intend to evaluate some other biological activities, such as wound-healing, antimalarial, antiviral, anti-cancer activity.

\section{ACKNOWLEDGEMENT}

The authors are thankful to Department of Biotechnology, Jamia Millia Islamia, New Delhi, India for providing the infrastructure to carry out the proposed research work.

\section{CONFLICTS OF INTERESTS}

The authors declare that they have no conflict of interest. It has not been published elsewhere. That it has not been simultaneously submitted for publication elsewhere. All authors agree to the submission to the journal.

\section{AUTHOR CONTRIBUTION}

Tooba Naz Shamsi: Concept, Data collection, and analysis, drafting article, writing manuscript.

Romana Parveen: Data collection and analysis, revision of the article, editing of the manuscript

Afaque Ahmad: Data collection, editing of the manuscript

Archoo Sajida: Sample and data collection, experimental work

Dr. Sadaf Fatima: Design of the work, data analysis, revision of the manuscript, final approval of the manuscript to be submitted for publication.

\section{REFERENCES}

1. Sharma A, Shanker C, Tyagi L, Singh M, Rao CV. Herbal medicine for market potential in India an overview. Acad J Plant Sci 2008;1:126-36.

2. Rajini M, Kanaki NS. Phytochemical standardization of herbal drugs and polyherbal formulations. In: Ramawat KG, Merillon JM. editors. Bioactive molecules and medicinal plants. Springer Berlin Heidelberg; 2008. p. 349-69.

3. Pifferi G, Santoro P, Pedrani M. Quality and functionality of excipients. Farmaco 1999;54:1-14.

4. Shinde VM, Dhalwal K, Potdar M, Mahadik KR. Application of quality control principles to herbal drugs. Int J Phytomed 2009;1:4-8.

5. Singh S, Soni GR. WHO expert committee on biological standardization. Indian J Med Res 2004;120:497-8.

6. Street RA, Stirk WA, Van SJ. South African traditional medicinal plant trade-Challenges in regulating quality, safety and efficacy. J Ethnopharmacol 2008;119:705-10.

7. Wong SK, Lim YY, Chan EWC. Antioxidant properties of hibiscus species variation, altitudinal change costal influence, and floral color change. J Trop For Sci 2009;21:307-15.

8. Nair R, Kalariya T, Sumitra C. Antibacterial activity of some selected Indian medicinal flora. Turkish J Biol 2005;29:41-7.

9. Khan M, Wassilew SW. Natural pesticides from the neem tree and other tropical plants. Eds. Schmutterer H, Asher KRS, Germany: Digitalverlag GmbH; 1987. p. 645-50.

10. Kumar A, Ilavarasan R, Jayachandran T, Deecaraman M, Aravindan P, Padmanabhan N, et al. The anti diabetic activity of Syzygium cumini seed and its isolate compounds against streptozotocin induced diabetic rats. J Med Plant Res 2008;2:246-9.

11. Singh N, Gupta M. Effect of ethanolic extract of Syzygium cumini seed powder on pancreatic islets of alloxan diabetic rats. Indian J Exp Biol 2007;45:861-7.

12. Kumar A, Ilavarasan R, Jayachandran T, Deecaraman M, Kumar MR, Aravindan P, et al. Anti-inflammatory activity of Syzygium cumini seed. Afr J Biotechnol 2008;7:941-3.

13. Jagetia GC, Baliga MS, Venkatesh P. Influence of seed extract of Syzygium cumini (Jamun) on mice exposed to different doses of $\gamma$-radiation. J Radiat Res 2005;46:59-65.

14. Watanabe T, Rajbhandari KR, Malla KJ, Yahara S. A handbook of medicinal plants of Nepal. Kobfai Publishing Project, Bangkok, Thailand; 2005.

15. Barbade KD, Datar KG. Antibacterial activity, free radical scavenging potential, phytochemical investigation and in vivo 
toxicity studies of medicinal plant Embelia basal (R. and S.) A. Dc. Asian J Pharm Clin Res 2015;8:171-7.

16. Mizushima Y, Kobayashi M. Interaction of anti-inflammatory drugs with serum proteins, especially with some biologically active proteins. J Pharm Pharmacol 1968;20:169-73.

17. Oyedepo 00, Femurewa AJ. Anti-protease and membrane stabilizing activities of extracts of Fagra zanthoxiloides, Olax subscorpioides, and Tetrapleura tetraptera. Int J Pharmacogn 1995;33:65-9.

18. Jambunathan N. Determination and detection of reactive oxygen species (ROS), lipid peroxidation, and electrolyte leakage in plants. Methods Mol Biol 2010;639:292-8.

19. Santhosh W, Goveas SW, Abraham A. Evaluation of antimicrobial and antioxidant activity of stem and leaf extracts of Coscinium fenestratum. Asian J Pharm Clin Res 2013;6:218-21.

20. Sudha G, Priya MS, Shree RI, Vadivukkarasi S. In vitro free radical scavenging activity of raw Pepino fruit (Solanum muricatum). Int J Curr Pharm Res 2011;3:137-40.

21. Moron MS, Depierre JW, Mannervik B. Levels of glutathione, glutathione reductase and glutathione S-transferase activities in rat lung and liver. Biochim Biophys Acta 1979;582:67-78.

22. Saeed M, Muhammad N, Khan H, Khan SA. Analysis of toxic heavy metals in branded Pakistani herbal products. J Chem Soc Pak 2010;32:471-5.

23. Saeed M, Muhammad N, Khan H, Zakiullah. Assessment of hazardous heavy metals content of branded Pakistani herbal products. Trop J Pharm Res 2011;10:499-506.

24. Negi JS, Singh P, Rawat B. Chemical constituents and biological importance of swertia: a review. Curr Res Chem 2011;3:1-15.

25. Ghosh P, Mandal A, Chakraborty P, Rasul MG, Chakraborty M, Saha A. Triterpenoids from Psidium guava with biocidal activity. Indian J Pharma Sci 2010;72:504-7.
26. Chung PY, Navaratnam P, Chung LY. Synergistic antimicrobial activity between pentacyclic triterpenoids and antibiotics against Staphylococcus aureus strains. Ann Clin Microbiol Antimicrob 2011;10:25.

27. Rio DA, Obdululio BG, Casfillo J, Marin FG, Ortuno A. Uses and properties of citrus flavonoids. J Agric Food Chem 1997; 45:4505-15.

28. Salah N, Miler NJ, Pagange G, Tijburg L, Bolwell GP, Rice E, et al. Polyphenolic flavonoids as the scavenger of aqueous phase radicals as the chain breaking antioxidant. Arch Biochem Broph 1995;2:339-46.

29. Rabi T, Bishayee A. Terpenoids, and breast cancer chemoprevention. Breast Cancer Res Treat 2009;115:223-39.

30. Wagner $\mathrm{KH}$, Elmadfa I. Biological relevance of terpenoids: overview focusing on mono-di and tetraterpenes. Ann Nutr Metab 2003;47:95-106.

31. Sultana N, Ata A. Oleanolic acid and related derivatives as medicinally important compounds. J Enzyme Inhib Med Chem 2008;23:739-56.

32. Theis $\mathrm{N}$, Lerdau M. The evolution of function in plant secondary metabolites. Int J Plant Sci 2003;164:93-103.

33. United States Department of Agriculture. Center for Nutrition Policy and Promotion. Dietary Guidelines for Americans. National Academy Press: Washington DC: USA; 2010.

34. Mohamed STK, Azeem AK, Dilip C, Sankar C, Prasanth NV, Duraisami R. Anti-inflammatory activity of the leaf extracts of Gendarussa vulgaris Nees. Asian Pac J Trop Biomed 2011;1:147-9.

35. Kahkonen MP, Hopia A, Vuorela HJ, Rauha JP, Pihlaja K, Kujala $\mathrm{TS}$, et al. Antioxidant activity of plant extracts containing phenolic compounds. J Agric Food Chem 1999;47:3954-62.

36. Cushnie TP, Lamb AJ. Antimicrobial activity of flavonoids. Int J Antimicrob Agents 2005;26:343-56. 